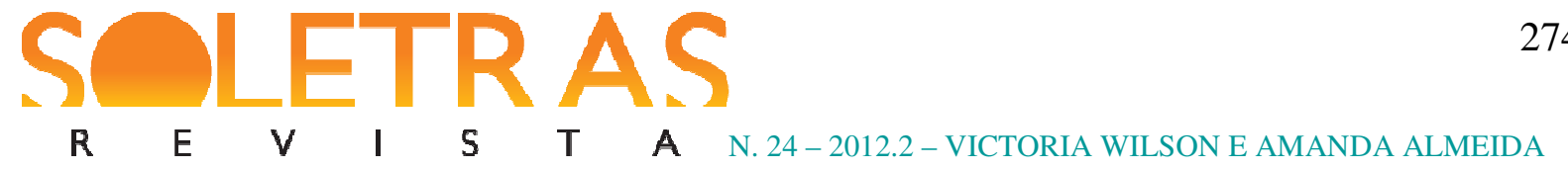

\title{
As condições de felicidade e o trabalho de faces em entrevista por $e$ - mail
}

\author{
Victoria Wilson da Costa Coelho ${ }^{1}$ \\ Amanda Dinucci Almeida ${ }^{2}$
}

\begin{abstract}
Resumo: Tendo em vista o papel da polidez nas interações sociais, esse artigo pretende refletir sobre a importância da polidez em situações interacionais específicas como a entrevista por e-mail que demandam rearranjos e reconstruções de papéis e imagens sociais e estratégias de preservação de face na condução das informações recebidas e do modo como são posteriormente publicadas e divulgadas em jornais. Na entrevista por e-mail, se por um lado o jornalista alcança sua finalidade comunicativa, na publicação tradicional, com mais facilidade, por outro, o entrevistado elabora as respostas com mais atenção e cautela, pois há mais tempo para trabalhar em prol da proteção de sua face. Observa-se, com isso, que a entrevista jornalística de alguma forma ritualizada sofre uma variação e, nessa complexa estrutura de participação que se estabelece entre os interactantes, se faz necessário identificar as condições de felicidade do gênero. A análise desenvolve-se à luz da Sociolinguística Interacional, de modo que seja possível contribuir para a discussão e resolução de problemas de ordem pragmática e social relacionados a esse gênero que, embora seja de formação recente, tem uso cada vez mais corrente na sociedade contemporânea.
\end{abstract}

Palavras-chaves: Polidez. Interação. Face. Entrevista por e-mail. Jornalismo.

\section{Introdução}

Desde o seu lançamento, o conceito de gênero foi revisitado diversas vezes, fazendo emergir uma área de pesquisa especificamente voltada para esse objeto. A profícua literatura e o reconhecimento em documentos oficiais que apontam diretrizes pedagógicas são indicativos da vastidão dessa pesquisa, mas não de seu esgotamento.

\footnotetext{
${ }^{1}$ Doutora em Letras (Linguística) pela Pontifícia Universidade Católica do Rio de Janeiro (2000). Concluiu pósdoutoramento no Programa de Pós-graduação em Educação da Universidade Federal Fluminense (2009). É professora associada de Linguística da Faculdade de Formação de Professores da Universidade do Estado do Rio de Janeiro. Participa do grupo de pesquisa "Linguagem, Cultura e Práticas Educativas", da Universidade Federal Fluminense; é membro do Diretório "Linguagem, Identidades, Ensino" (FFP-UERJ). É conselheira da AsselRio. Tem experiência na área de Letras, com ênfase em Linguística Aplicada, campo de pesquisa que abarca ensino e aprendizagem de língua portuguesa; letramento acadêmico; discurso e interação em contextos institucionais. E-mail: victoriawilson@ superig.com.br.

${ }^{2}$ Possui graduação em Letras (Português/Inglês) pela Universidade do Estado do Rio de Janeiro (2011). Atualmente é estudante do mestrado em Estudos de Linguagem na Pontifícia Universidade Católica do Rio de Janeiro. Participa do grupo de pesquisa Discurso, Interação e Trabalho desta instituição. Tem experiência na área de Linguística, com ênfase em Pragmática e Sociolinguística Interacional e seus interesses de pesquisa envolvem tópicos como interação em contextos institucionais; linguagem e identidade na esfera pública; e discursos profissionais.
} 
$\begin{array}{llllllll}\text { R } & \text { E } & \text { V } & \text { I } & \text { S } & \text { T } & \text { A } & \text { N. 24-2012.2-VICTORIA WILSON E AMANDA ALMEIDA }\end{array}$

Em primeiro lugar, cabe esclarecer que o repertório de gêneros é ilimitado, devido ao seu caráter dinâmico e maleável. Isto é, embora alguns estejam firmados e sejam resistentes à variação, outros estão ainda em formação e há aqueles que são simplesmente circunstanciais. Nessa perspectiva, não cabe a proposta de descrevê-los e manipulá-los objetivamente, desconsiderando seu aspecto pragmático. Quanto a essa relação entre os gêneros e os sujeitos, Bakhtin (2003) assinala que haverá tantos gêneros de discurso quanto houver atividades humanas. Na sociedade contemporânea, os artefatos tecnológicos abrem novas formas de interação, promovendo os cybergêneros. Visando ao alcance das massas, mas apoiada em ausência física dos interactantes e marcada, muitas vezes, por assincronia, a interação virtual torna a estrutura de participação ainda mais complexa. Para analisar os gêneros virtuais é necessário, portanto, considerar os aparatos midiáticos envolvidos na sua estruturação e os aspectos relativos à psicologia de seus usuários, no sentido de interação (BONINI, 2000).

Dentre eles, interessa-nos a entrevista por $e$-mail, uma situação social que prescinde do encontro face-a-face. Realizamos, assim, um estudo de caso baseado em uma entrevista da cantora Paula Toller concedida a uma colunista do jornal Folha de São Paulo,-publicada em maio de 2011. A artista afirma que optou pela entrevista por e-mail para poupar sua voz, mas observam-se outros fatores determinantes para tal escolha, ao entrarmos na segunda década do século XXI, por conta das novas tecnologias virtuais, por exemplo.

Por um lado, o jornalista alcança sua finalidade comunicativa, a publicação, com mais facilidade. Por outro, o entrevistado trabalha em prol da proteção de sua face, já que pode elaborar as respostas com mais atenção e cautela. Com isso, a entrevista jornalística, de alguma forma ritualizada, sofre uma variação. Ou seja, embora a conversa permaneça orientada para o mesmo objetivo de uma entrevista tradicional, o arranjo social organizado e compartilhado se altera.

Quando não ocorre a publicação, configura-se claramente o insucesso da interação. No entanto, mesmo que esse propósito comunicativo seja atingido, pode não haver êxito na interação. Logo, se faz necessário identificar as condições de felicidade ao manipularmos o gênero, visto que o uso da entrevista por e-mail é cada vez mais corrente, é de relevância social esse procedimento.

Cabe ainda analisar o trabalho de faces na interação, pois o entrevistador deve, não apenas, usar a polidez como estratégia de preservação da face pessoal, como salvar a face da instituição que representa; enquanto o entrevistado, como é, em geral, uma pessoa pública, tem como uma das finalidades principais a projeção da sua imagem. A entrevista, como um 
$\begin{array}{llllllll}\text { R } & \text { E } & \text { V } & \text { I } & \text { S } & \text { T } & \text { A } & \text { N. 24-2012.2-VICTORIA WILSON E AMANDA ALMEIDA }\end{array}$

encontro face-a-face, situa os interactantes em posições vulneráveis. Afinal, uma vez que apresentam sua imagem publicamente, o que se pretende mostrar pode não ser evidenciado, ao passo que aquilo que é desejável não exibir corre o risco de ser notado. Adotar o e-mail como forma de estabelecer esse encontro é um procedimento que visa reduzir esses riscos. É, portanto, uma estratégia para alcançar o sucesso comunicativo. Não há, contudo, nenhuma estratégia capaz de impedir a ameaça virtual que marca toda interação. Interagir é pôr-se em risco. Mas, se não é possível neutralizar essa ameaça, ao menos os falantes tentam enfraquecê-la. Isso se torna particularmente relevante no caso de uma celebridade. Ela é especialmente vulnerável, pois pode ser entendida como uma figura pública que ocupa o espaço de visibilidade da mídia, capaz de afetar os indivíduos, os quais, por sua vez, agem a partir dessa afetação.

$\mathrm{Na}$ entrevista realizada com a cantora Paula Toller, cria-se uma situação interativa (enquadre) que abarca a troca explícita entre a entrevistadora e a entrevistada e uma subinteração que se encaixa na primeira, entre a entrevistada e seus fãs. É possível afirmar que a artista constrói seu discurso apoiada em uma projeção imaginada dessa audiência. $\mathrm{O}$ alinhamento com esse público é notório por sua preparação, caracterizando-o como um discurso público, endereçado aos fãs.

O trabalho de face nesse arranjo interacional nos desperta interesse uma vez que percebemos que a preocupação de preservar a imagem pública acompanha permanentemente qualquer indivíduo e, no caso de uma entrevista, o esforço de "encenação" abordado por Goffman (1981) se exacerba. Notamos ainda que, na entrevista por e-mail, caso a face do outro seja ferida não haverá uma maneira imediata de reparar o dano, o que pode comprometer o objetivo maior do jornalista: a publicação. Por isso, os participantes deverão adotar estratégias diferenciadas em relação a uma entrevista tradicional.

De fato, nota-se que a entrevistada adota estratégias relacionadas à construção de sua imagem pública, procurando defender-se dos atos de ameaça à face e invasão de seu território pela jornalista. Ambas, no entanto, entrevistadora e entrevistada, concentram-se na representação de seus respectivos papeis sociais, negociando faces e identidades construídas nesse tipo de interação. No movimento de ajuste das expectativas dos participantes dessa interação por e-mail, é necessário que ambos contribuam para que se alcancem as finalidades comunicativas que estão em jogo. Se isso não ocorrer, e o encontro entre entrevistado e entrevistador se caracterizar como um caso de insucesso comunicativo, serviços como os de 
$\begin{array}{llllllll}\text { R } & \text { E } & \text { V } & \text { I } & \text { S } & \text { T } & \text { A } & \text { N. 24-2012.2-VICTORIA WILSON E AMANDA ALMEIDA }\end{array}$

um Ombudsman $^{3}$ podem ser acionados para que sejam realizadas intervenções reparadoras de face. É o que ocorre no caso que analisaremos.

\section{Caracterização do caso em estudo}

Esse trabalho trata das seguintes situações (disponíveis no anexo): (i) Entrevista da cantora Paula Toller concedida à colunista Mônica Bergano do jornal Folha de São Paulo (na íntegra, versão não publicada no jornal); (ii) Texto de divulgação da entrevista, publicado no jornal Folha de São Paulo, na coluna da referida jornalista (adaptação da entrevista pela jornalista); (iii) Nota no blog oficial da artista, após a publicação, qualificando-a como "lamentável"; (iv) A resposta do Ombudsman do jornal Folha de São Paulo à nota divulgada no blog da artista. A coluna foi publicada no dia $1^{\circ}$ de maio de 2011 e três dias depois houve a publicação da resposta do Ombudsman. Todo o material foi disponibilizado no blog oficial da artista (www.paulatoller.com) no dia quatro de maio do mesmo ano.

Para analisar, então, como os envolvidos na interação verbal usam os recursos linguísticos para alcançar sua (s) finalidade (s) numa entrevista por e-mail, escolhemos a entrevista realizada com a cantora Paula Toller, primeiramente porque foi publicada em seu blog oficial. Há de se tomar essa precaução com as fontes especialmente quando se trata da interação virtual. Ademais, há uma situação de conflito quando o texto é publicado. O insucesso comunicativo torna este material objeto de indagação acadêmica. Identificar as causas desse nó pode contribuir para percebermos que elementos de uso e compreensão da linguagem são capazes de promover a eficácia dos enunciados proferidos nesse contexto interacional, para que não se chegue a um conflito como o que se apresenta em nosso corpus.

Com base nesse material, realizaremos um estudo de caso, pautado por uma análise qualitativa e interpretativa, no qual investigaremos: (i) o arranjo interacional: como se organiza a estrutura de participação, que enquadres e alinhamentos emergem e de que forma os mesmos se encaixam na entrevista; (ii) as condições de felicidade: que máximas conversacionais são atendidas ou deixam de ser e que impacto isso tem na interação; (iii) a elaboração das faces: que estratégias de (im) polidez são utilizadas e como se concebe a atividade ameaçadora da face na publicação.

\footnotetext{
${ }^{3}$ Num jornal, o Ombudsman é responsável por receber, investigar e encaminhar as queixas dos leitores; realizar uma crítica interna; e, uma vez por semana, produzir uma coluna de comentários críticos sobre os meios de comunicação, na qual o próprio jornal deve ser um dos alvos privilegiados.
} 
$\begin{array}{llllllll}\text { R } & \text { E } & \text { V } & \text { I } & \text { S } & \text { T } & \text { A } & \text { N. 24-2012.2-VICTORIA WILSON E AMANDA ALMEIDA }\end{array}$

Cabe esclarecer que não buscamos formular uma definição para caracterizar a entrevista por e-mail, nesse estudo, pois nosso objetivo está voltado para os processos de elaboração de face construídos nessa interação. No entanto, buscamos em Bonini (2000), algumas orientações sobre entrevistas jornalísticas. O diálogo e os tópicos como traços principais da entrevista são alterados drasticamente, pois as perguntas são emitidas em bloco. Bonini retoma, segundo os manuais de redação e estilo jornalísticos, algumas regras do tipo: seja incisivo e seja cauteloso. Reproduzimos do autor o seguinte:

a) ser incisivo: "Você pode fazer perguntas diretas e incisivas ao entrevistado sem que o clima de cordialidade da conversa seja prejudicado" (O Estado de São Paulo, p. 31). "Durante a entrevista o jornalista tem o direito de perguntar tudo, inquirir, reinquirir e contrapor informações fatos e evidências" (Folha de São Paulo, p. 110). (g. m); b) ser cauteloso: "Procure evitar atritos com o entrevistado; quem sairá perdendo será sempre o leitor" (O Estado de São Paulo, p. 31). (g. m.) "[...] não deve agredir o entrevistado (Folha de São Paulo, p. 110)." (g. m.) (BONINI, 2000, p. 9).

Para o autor, esse tipo de esquema de entrevista leva em conta regras pautadas em uma interação face-a-face. Esse tipo de padrão acaba também sendo reproduzido na entrevista por e-mail, em que "o entrevistador, como em uma entrevista jornalística prototípica, elabora questões provocativas para que a entrevistada revele conteúdos novos" (BONINI, 2000, p. 9). $\mathrm{Na}$ entrevista por $e$-mail, a mudança tópica não se sujeita ao sistema de troca de turnos como numa conversação face a face, pois as perguntas são enviadas em bloco para o entrevistado que, recebidas, são por ele organizadas. Nota-se que a conversação não é uma simples sucessão/alternância de tópicos conversacionais. Seria possível abordar mais de um assunto, assim como se poderia privilegiar um assunto específico. Mas essas variações ou a manutenção tópica não se manifestam aleatoriamente. Wilson (2008, p. 108) assinala que "a continuidade tópica varia em função dos interesses e objetivos dos interlocutores". $\mathrm{Na}$ entrevista com a cantora Paula Toller, apresentam-se bem delimitados os tópicos: saúde, vaidade, relação com os fãs, nível de exigência profissional, rotina, entre outros selecionados por Mônica Bergamo, que, selecionados pela cantora, são respondidos um a um.

Num trecho de nosso corpus, por exemplo, primeiro a jornalista pergunta: "Quando e como você diagnosticou diabetes? O que mudou na sua vida desde então?”. O tema (tópico) escolhido para a discussão é saúde. Na sequência, pergunta-se: "Há quantos anos você faz análise? O que você enxerga como resultado dessa experiência (inclusive canções)?”. Esse subtópico desencadeia uma conversa mais íntima, pois se trata de uma questão mais pessoal. No entanto, esse ainda se relaciona aos cuidados médicos. 
$\begin{array}{llllllll}\text { R } & \text { E } & \text { V } & \text { I } & \text { S } & \text { T } & \text { A } & \text { N. 24-2012.2-VICTORIA WILSON E AMANDA ALMEIDA }\end{array}$

Quando se trata de um desses temas, há na entrevista uma continuidade tópica que estrategicamente se desenrola numa sequência de, primeiramente, um tópico mais ameaçador - Quando e como você diagnosticou diabetes? - e, posteriormente, um subtópico para mitigar a ação ameaçadora do primeiro, na tentativa de mostrar solidariedade e empatia com a cantora: $O$ que mudou na sua vida desde então?

Observamos que a entrevistadora oscila entre atos que põem em risco a face da cantora a atos que visam a atenuar esses riscos de modo que a entrevistada possa responder às perguntas sem se sentir invadida ou ofendida. Esse tipo de estratégia utilizada pela jornalista parece caracterizar uma antecipação, visando a neutralizar os efeitos da "invasão" e limitar reações indesejáveis por parte da artista.

Nesse caso, torna-se evidente que a topicalidade, isto é, a determinação dos tópicos ao quais corresponderá cada pergunta da entrevista, tem uma motivação pragmática. Por meio dessa escolha realizada pela entrevistadora minimizam-se (ou tenderiam à minimização das) as possibilidades de conflito. Essa é uma estratégia para que o efeito perlocutório dos atos de fala não seja mal sucedido, de modo que a cantora não coloque em risco sua face negativa. Uma vez que coopera para essa preservação, é uma estratégia de polidez negativa. Por outro lado, segundo Bonini:

[...] diferentemente da entrevista jornalística padrão face-a-face, as questões não constituem textos isolados que podem ser regulados pelas intervenções do entrevistador, mas um texto único, cuja interpretação sai de seu controle. Ao leitor do jornal, entretanto, o processo interacional estará velado, e sua leitura seguirá os padrões de uma entrevista comum. Ele pode inclusive chegar ao questionamento: "como o jornalista deixou a entrevista chegar a tal ponto?" (BONINI, 2000, p. 9).

\section{Base teórica}

A reflexão apresentada neste trabalho se dá à luz da Sociolinguística Interacional. Sendo assim, privilegia as relações entre língua, cultura e sociedade. Goffman (1964) estrutura esse conhecimento a partir da observação do que chama de situação social de interação. Segundo ele, isso ocorre sempre que dois ou mais falantes se encontram face-a-face. Esse conceito pode ser bem aplicado à sociedade no qual foi lançado, mas no século XXI é preciso revisitálo. Afinal, as atividades discursivas sofreram profundas transformações à medida que a comunicação se modernizou. Mas cabe reconhecer a importância de que se tenha elegido a partir de então a situação como foco de análise, contribuição decisiva para a Pragmática. 
$\begin{array}{llllllll}\text { R } & \text { E } & \text { V } & \text { I } & \text { S } & \text { T } & \text { A } & \text { N. 24-2012.2-VICTORIA WILSON E AMANDA ALMEIDA }\end{array}$

Segundo os estudos nessa área, a pragmática é a ciência do uso linguístico. De acordo com Marcondes (2005, p. 10), "essa ciência consiste na nossa experiência concreta da linguagem, nos fenômenos linguísticos com que efetivamente lidamos." Sob essa orientação e com vistas a avançar conhecimentos sobre as relações entre a sociedade e a linguagem, esse trabalho se vincula aos pressupostos teóricos doravante elencados.

\subsection{Os atos de fala e a concepção performativa da linguagem}

O filósofo inglês John Austin rejeita uma concepção de uso da língua como a construção de inventários ensimesmados em estruturas linguísticas. Em seu livro, Quando dizer é fazer (1962), ao apresentar a Teoria dos Atos de Fala, Austin preconiza a "concepção performativa da linguagem", lançando os germes para que se considere qualquer frase da língua como uma ação sobre o real e não apenas sua representação.

Segundo ele, todo enunciado corresponde a três atos simultâneos realizados pelo falante. Evidentemente, há um ato locutório já que se trata de uma comunicação verbal, ou seja, é necessário articular os níveis fonético, sintático e de referência da língua. Mas o ato que protagoniza o dizer para Austin é o ato ilocutório. Esse se associa ao modo como o enunciado é proferido e a uma projeção de sua força performativa. Por fim, há o ato perlocutório, que se caracteriza pelas "conseqüências do ato [central, a saber, ilocutório] em relação aos sentimentos, pensamentos e ações dos ouvintes, ou do falante, ou de outras pessoas" (AUSTIN, 1962, p. 101).

Vicejarão na obra de Searle, mais tarde, as sementes dos estudos de Austin. O autor aponta, então, um marcador da força ilocucional. Mas assinala que "frequentemente, nas situações concretas do discurso, é o contexto que permitirá fixar a força ilocucional da enunciação, sem que haja necessidade de recorrer ao marcador explícito apropriado" (SEARLE, 1984, p. 44). Ele adverte ainda que para garantir a eficácia do ato de fala, o mesmo deve ser enunciado sem que se percam de vista as circunstâncias em que será proferido.

$\mathrm{Na}$ esteira de concepção de linguagem não essencialista de Austin, figura tutelar dos desdobramentos da Pragmática, Searle evidencia que os elementos de uso e de compreensão da linguagem não são apenas proposições que possuem condições de verdade, mas são atos de fala com condições de felicidade (ou sucesso) e infelicidade (ou fracasso). Isto é, um enunciado não deve simplesmente ser avaliado como verdadeiro ou falso, mas devemos avaliar suas condições de produção e notar se são apropriadas ao (s) efeito (s) desejado (s). 
$\begin{array}{llllllll}\text { R } & \text { E } & \text { V } & \text { I } & \text { S } & \text { T } & \text { A } & \text { N. 24-2012.2-VICTORIA WILSON E AMANDA ALMEIDA }\end{array}$

Hoje, no entanto, há uma crítica por parte de estudiosos interacionistas em relação à teoria clássica desenvolvida por Austin e Searle. Para eles, cada ato de fala deveria ser considerado parte de uma troca linguística, mas há uma focalização excessiva na figura do falante, em seu aspecto individual. Contudo, Austin (1962, p. 10) enfatiza a natureza contratual desses atos e indica, a priori, que os aspectos interacionais de sua realização devem ser considerados.

\subsection{As implicaturas e máximas conversacionais de Grice}

O filósofo americano Grice (1975), cujos estudos datam do século XX, ao caracterizar a língua em uso como um sistema cooperativo entre falante e ouvinte, postulou que toda conversação tende a ser governada por certos princípios. De acordo com o estudioso, cada um deve fazer a sua contribuição num encontro, correspondendo ao que se espera, no momento em que é solicitado, de modo que seja possível alcançar o (s) propósito (s) comunicativo (s).

Para que chegasse a esse postulado, conhecido como o princípio de cooperação, Grice observou que existem dois tipos de implicatura nos enunciados da língua. Essa análise foi decisiva para o desenvolvimento da Pragmática. Quando o que propicia uma boa interpretação do ouvinte são os elementos do próprio sistema linguístico, estamos diante de implicaturas convencionais. Mas, quando o contexto extralinguístico é determinante para a produção de sentido, existem as chamadas implicaturas conversacionais. Em nenhum desses casos o significado é dito, mas, no primeiro, é "indicado" pelo material linguístico; enquanto, no último, recorrer ao suporte linguístico não é tão eficiente, pois o que é comunicado está muito além do que reside na estrutura do enunciado. O significado, nesse caso, depende principalmente do conhecimento da situação, compartilhado pelo falante e pelo ouvinte.

Grice reconheceu seu interesse por essas implicaturas (conversacionais) e admitiu que o significado desses enunciados depende do contexto, pois é importante saber, por exemplo, quem os enuncia, para quem o faz e qual é sua finalidade. Contudo, o autor afirma que as implicaturas conversacionais são "essencialmente conectadas com traços gerais do discurso" (GRICE, 1975). Ainda que as leis que regulam a conversação e que viabilizam a manifestação de implicaturas conversacionais não pertençam ao sistema linguístico, elas regem o uso da língua. Para Grice, o dizer também vai além do dito e é resultado de uma intenção de quem enuncia, em que cabe ao interlocutor calcular o significado do que foi dito relacionando-o ao contexto comunicativo, baseando-se no cumprimento ou não das leis da conversação. Nessa 
$\begin{array}{llllllll}\text { R } & \text { E } & \text { V } & \text { I } & \text { S } & \text { T } & \text { A } & \text { N. 24-2012.2-VICTORIA WILSON E AMANDA ALMEIDA }\end{array}$

perspectiva, embora a intencionalidade focalize o falante, é o ouvinte quem deve atuar no sentido de desvendar o que está implícito. Em suma, o que é posto na conversação é importante, mas nem sempre o que um sujeito quer dizer é o que normalmente se pretende comunicar com determinada sentença. Isto é, o significado comum pode ser diferente do significado de quem enuncia algo numa circunstância específica. Logo, o contexto em que ocorre a interação é relevante. Afinal, é possível violar uma das leis da conversação e ainda assim estar operando com o princípio da cooperação. Em casos assim, surgem as implicaturas conversacionais, que não caracterizam de forma alguma um erro de comunicação.

No entanto, essa possibilidade não nega a validade das regras, cuja importância é notória para o equilíbrio social que os indivíduos buscam nas interações cotidianas. Na teoria de Grice (1975), portanto, o princípio da cooperação pode ser compreendido a partir das seguintes máximas conversacionais, distribuídas em quatro categorias: (a) máxima da quantidade: seja informativo na medida apropriada, ou seja, não contribua com mais nem menos do que é solicitado; (b) máxima da qualidade: não diga o que você considera ser falso ou que você não pode comprovar; (c) máxima da relação: contribua com aquilo que é relevante de acordo com o (s) propósito (s) comunicativo (s) que estão em jogo na interação; (d) máxima do modo: Não seja impreciso ou ambíguo e evite digressões desnecessárias.

A máxima do modo, por exemplo, pode ser um expoente quando se trata da entrevista por e-mail, pois, o entrevistador envia um bloco de perguntas ao entrevistado. Caso não haja clareza suficiente, a face do outro pode ser ferida e não haverá uma maneira imediata de reparar o dano - uma possibilidade vigente numa entrevista face-a-face. Isso pode comprometer o objetivo maior do jornalista: a publicação. Esses conceitos podem ser, assim, relevantes para esse trabalho.

\subsection{A face e as estratégias de polidez}

Todo encontro rompe, na verdade, um equilíbrio pré-existente e os atos de fala que nele ocorrem são de alguma forma ameaçadores às faces dos interlocutores. Em toda interação, os participantes parecem trabalhar a favor do equilíbrio e da harmonia, por isso Goffman postula como regras sociais o auto-respeito e a consideração como comportamentos de ajustes interacionais e manutenação da face. Para esse autor, a face é "valor social positivo, que uma pessoa reclama para si", isto é, "a imagem do self delineada em termos de atributos sociais aprovados" (GOFFMAN, 1980, p. 77). 
$\begin{array}{llllllll}\text { R } & \text { E } & \text { V } & \text { I } & \text { S } & \text { T } & \text { A } & \text { N. 24-2012.2-VICTORIA WILSON E AMANDA ALMEIDA }\end{array}$

Os estudos sobre polidez receberam diferentes enfoques teóricos, mas podemos apontar, conforme Oliveira (2008, p. 13), quatro visões principais, que aqui sintetizamos: (i) polidez como norma social; (ii) como uma máxima conversacional; (iii) como uma regra pragmática; (iv) como um trabalho de preservação de face.

Esse artigo orienta-se para os trabalhos de preservação de face desenvolvido por Brown e Levinson (1987), que postulam o Princípio Universal da Polidez, baseados no conceito de face derivado de Goffman. Para ambos os autores, face é a imagem pública que qualquer sujeito sustenta e é constituída de: face negativa e face positiva - o que Goffman chama, $a$ priori, de "território" e "face", respectivamente. Sua elaboração, duplamente orientada, é uma necessidade social que requer esforço contínuo dos indivíduos. A polidez consiste justamente nesse esforço de manter e reparar a própria face e a do outro. Para Holanda (1995, p. 147), a polidez "equivale a um disfarce que permitirá a cada qual preservar inatas sua sensibilidade e suas emoções", diferentemente da cordialidade que seria a manifestação "pura" e explícita dos sentimentos.

A face negativa se constitui dos territórios (corporal, material, espacial, temporal ou mental) do indivíduo. Perguntas "indiscretas", ofensivas, ou atos que envolvem pedidos, reclamação, censura, etc. servem como exemplo de atos contrários e impositivos capazes de ferir a face negativa do indivíduo. Sendo assim, o respeito à privacidade do outro e à sua liberdade caracterizam a polidez negativa, isto é, o esforço de manter essa face do interlocutor preservada. Já a face positiva é o conjunto de imagens valorizadas de uma pessoa e está relacionada ao desejo e à necessidade de aprovação. Se o emissor faz uma confissão, por exemplo, essa ação fere sua própria face positiva. Mas, ações de reconhecimento da imagem que o interlocutor constrói e tenta impor na interação, como elogios, são estratégias de polidez positiva, pois correspondem à valorização do outro. No entanto, interagir é pôr-se em risco, isto é, toda interação é potencialmente ameaçadora da face. Por isso, o indivíduo deve cooperar para o êxito da comunicação. Assim, minimizam-se as possibilidades de conflito e evita-se, por conseguinte, o que Goffman denomina "perda da face", quando se perde o prestígio social.

Se as faces são paradoxalmente alvo de ameaças contínuas e objeto de um desejo de preservação, é necessário um trabalho de figuração (GOFFMAN, 1980) que designa tudo que uma pessoa faz para preservar a face dos participantes de uma interação, inclusive a própria. Para Brown e Levinson, essa realidade paradoxal se revela com a implementação de variadas estratégias de polidez. Nesse sentido, a polidez surge como um meio de conciliar o desejo e 
$\begin{array}{llllllll}\text { R } & \text { E } & \text { V } & \text { I } & \text { S } & \text { T } & \text { A } & \text { N. 24-2012.2-VICTORIA WILSON E AMANDA ALMEIDA }\end{array}$

necessidade de face (face-want) com a condição ameaçadora dos atos de fala e a vulnerabilidade a que os indivíduos se sujeitam para interagir.

Em vista dos conflitos iminentes a que cada interação é ou está suscetível, os autores propõem quatro modos de se realizarem os atos: (i) fazer o ato diretamente; (ii) fazer o ato com reparação à face positiva; (iii) fazer o ato com reparação à face negativa; (iv) fazer o ato diretamente, com a violação das máximas de cooperação.

A entrevista, como um encontro face-a-face, coloca os interactantes em posições vulneráveis. Adotar o e-mail como forma de estabelecer esse encontro é um procedimento que visaria reduzir esses riscos e, consequentemente, funcionaria como uma estratégia para a preservação de faces, mas, como veremos, não suficientemente capaz de afastar a possibilidade de conflito entre as partes envolvidas. Afinal, não há estratégia capaz de impedir a ameaça virtual que marca toda interação. Mas, se não é possível neutralizá-la, ao menos os falantes têm a opção de enfraquecê-la. Nesse sentido, os conceitos de face e as estratégias de polidez propostas por Brown e Levinson são importantes para se pensarem e observarem as relações entre as pessoas.

É válido mencionar, contudo, que a impolidez também exerce uma função importante no cenário social, segundo Culpeper (1996). Pode ser parte integrante ou até mesmo exigência de certos contextos interacionais. Brown e Levinson (1987) consideram somente a polidez como algo estratégico, que se elabora quando se pretende estabelecer a harmonia interacional, mas a impolidez pode ser uma escolha estratégica, racional e elaborada também. Cabe, então, analisar quais os interesses envolvidos no desejo de evitar o descompasso ou até mesmo no desejo de ameaçar a face do outro na interação por parte de entrevistado e entrevistador.

\section{A entrevista e seus desdobramentos}

À luz da sociolinguística interacional, nessa parte do presente trabalho, analisaremos: a) as estratégias de polidez negativas utilizadas pela jornalista Mônica Bergamo na elaboração das perguntas que seriam enviadas para Paula Toller; b) o trabalho de figuração da cantora com vistas a cooperar para a comunicação com seus fãs e agregar atributos socialmente aprovados a seu self por meio de suas respostas; c) uma construção diferente da imagem de Paula Toller no texto de divulgação da entrevista, elaborado pela entrevistadora, e a geração de um conflito. 
$\begin{array}{llllllll}R & \text { E } & \text { V } & \text { I } & \text { S } & \text { T } & \text { A } & \text { N. 24-2012.2-VICTORIA WILSON E AMANDA ALMEIDA }\end{array}$

\subsection{Os processos de elaboração da face como construção de uma imagem pública}

\subsubsection{A construção de face realizada por Paula Toller}

Uma vez enviado o bloco de perguntas à artista e concedidas as respostas, verifica-se uma situação interativa que abarca a troca explícita entre a entrevistadora e a entrevistada e uma "sub-interação", que se encaixa na primeira, entre a entrevistada e seus fãs. $O$ alinhamento com esse público projetado é notório pela preparação do discurso, caracterizando-o como um discurso público, endereçado aos fãs. A cantora procura responder às perguntas propostas de modo objetivo, fazendo uso praticamente de todas as implicaturas conversacionais. Apesar da imposição dos atos de fala da jornalista (as perguntas muitas vezes são indiscretas, invasivas, sobretudo aquelas referentes à saúde física e mental como as do primeiro bloco abaixo), Paula Toller faz uso das máximas de quantidade, sendo informativa na medida certa; de qualidade, procurando ser verdadeira; de relação, indo ao cerne da questão: e de modo, evitando digressões desnecessárias. Vejamos como exemplo o primeiro bloco da entrevista:

Coluna Mônica Bergamo - Quando e como você diagnosticou diabetes? O que mudou na sua vida desde então?

Paula Toller - Fui diagnosticada com Diabetes tipo 1 em 2009, por acaso, numa consulta com o dermatologista que me trata há 20 anos. Eu estava magra demais e ele desconfiou. Foi um baque, mas agora já estou me adaptando, embora tenha que seguir uma rotina de alimentação e exercícios bem rígida, e usar insulina.

Coluna MB - Há quantos anos você faz análise? O que você enxerga como resultado dessa experiência (inclusive canções)?

PT - Análise evita enferrujar o cérebro. É bom para dar valor às coisas que realmente têm valor, e deixar rolar o que pode ser deixado rolar. Aos poucos você vai conhecendo melhor essa maquininha que diferencia os seres humanos dos outros seres. E dá um suporte para as inevitáveis barras pesadas. Eu tinha muito problema com inspiração pra escrever, era cheia de 'não-me-toques', agora, se tenho que escrever, vou lá e escrevo. É bem óbvio.

Nota-se que a cantora evita criar uma situação desarmônica com a jornalista, especialmente no tocante à primeira pergunta sobre o estado de sua saúde. Falar publicamente sobre a diabetes, dizer que toma insulina e de que foi um baque saber de sua enfermidade são respostas que transgridem a esfera pessoal. A cantora poderia ter se esquivado a responder, uma vez que a entrevista por e-mail daria a ela essa oportunidade. Ao contrário, percebeu que 
$\begin{array}{llllllll}\text { R } & \text { E } & \text { V } & \text { I } & \text { S } & \text { T } & \text { A } & \text { N. 24-2012.2-VICTORIA WILSON E AMANDA ALMEIDA }\end{array}$

a melhor maneira de manter o equilíbrio na interação era responder de modo claro, preciso e sem ambiguidades para satisfazer a entrevistadora e consequentemente a curiosidade de seus fãs. Logo, no conjunto das respostas, tornaram-se estratégias elegantes e amigáveis de interação, apesar da falta de tato e empatia da jornalista em logo de início introduzir assunto de natureza tão delicada e pessoal.

$\mathrm{O}$ mesmo se pode afirmar em relação à segunda pergunta referente à análise. A jornalista realiza um ato de ameaça à face on record, ou seja, diretamente. Perguntar sobre o tempo a que a cantora faz análise e se os resultados teriam sido satisfatórios pode causar forte constrangimento à entrevistada. Apesar da exposição pública a que artistas em geral são submetidos, perguntas como essas ferem a face negativa, porque o grau de invasão de território é muito alto e requer "jogo de cintura", às vezes bom humor e, também, no caso em questão, bom senso para não reagir de modo grosseiro, impolido ou explicitamente defensivo. Paula Toller não evita as respostas, porém sua explicação sobre a análise é genérica, "impessoal", coletiva: qualquer que pessoa que conhece ou faz análise poderia dar essa resposta. Nesse caso, a cantora faz uso de uma estratégia defensiva, extremamente polida: a esfera íntima e pessoal é preservada, mas a interação é mantida segundo um princípio autoregulador, como um ritual de comportamento, conforme postula Goffman (1980). De acordo com o autor, as ameaças à face, segundo esse princípio, seriam evitadas ou contornadas "de tal forma que os participantes, em conjunto, possam atingir seu objetivo comum, apesar de diferentemente motivados" (GOFFMAN, 1980, p. 94).

No terceiro bloco das perguntas, a jornalista novamente faz um ato de ameaça à face da cantora. Ela faz esse ato indiretamente, usando uma constatação genérica ("as pessoas que convivem com você dizem") a respeito da cantora para não se comprometer com a afirmação (você é "uma pessoa exigente e profissional"). Vejamos a pergunta: "As pessoas que convivem com você dizem que é uma pessoa 'exigente e profissional'. Você concorda? Acha que tem atitude diferente do padrão brasileiro?".

Paula Toller novamente responde de modo a contornar uma agressão sutil na pergunta da jornalista. Ela encara a pergunta, tomando-a como um elogio. Com isso, salva sua própria face, pois atribui um aspecto positivo às características observadas em si mesma. Observemos a resposta:

É um elogio, mas não comparo com os outros. Eu me exijo muito, eu sofro com as coisas, não durmo se tem algo errado. Tenho o prazer de trabalhar com gente talentosa e que se compromete. E faço muitos amigos entre os colegas. Pessoas por quem tenho o maior carinho e com quem saio para 


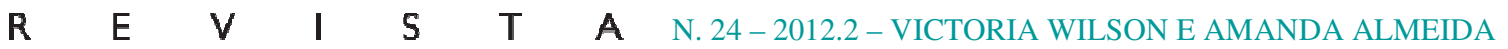

comer pizza. Eu adoro minha roda, poder jantar $1 \mathrm{~h}$ da manhã depois do show!

Cabe notar que, se ela afirmasse que o padrão brasileiro de comportamento é diferente do seu, estaria implicitamente ofendendo os próprios fãs, em sua grande maioria, brasileiros. Ao evitar a comparação na qual seria possível reforçar o estigma do brasileiro (ou de alguns) como negligente com os compromissos, ela evita um ato de ameaça à face coletiva. Opta simplesmente por responder "é um elogio, mas não comparo com os outros". A partir de então, coerentemente com essa afirmação, começa a explicar sua própria postura: "eu me exijo muito, eu sofro com as coisas, não durmo se tem algo errado". A resposta segue mantendo um alinhamento com o público e com a própria imagem que a cantora deseja sustentar: "Tenho o prazer de trabalhar com gente talentosa e que se compromete". Nesse trecho, a artista exagera o interesse, a aprovação e a simpatia por outro grupo com o qual também lhe interessa, o seu grupo, por quem mantém cumplicidade afetiva. Nota-se, portanto, que a polidez também se manifesta em mais uma resposta e há um esforço contínuo no movimento de preservação das faces.

Ao afirmar que gosta de ser elogiada, Paula Toller deixa clara sua preocupação em ter seus atributos reconhecidos. No entanto, em certos trechos é possível notar que há uma tentativa de passar a imagem de uma pessoa comum, como qualquer interlocutor. Isso pode configurar uma estratégia para encurtar as distâncias com o público. Observe a seguinte fala da cantora sobre sua rotina longe dos palcos, no terceiro bloco de perguntas:

Dois dias antes de qualquer show eu já estou me preparando, não tomo nem um drink, por exemplo. Antes de uma estréia como essa agora, então, eu já entro um mês antes no processo. Mas sair eu saio rápido, sou capaz de chegar de um show para 30 mil pessoas e fritar um ovo ainda maquiada e de salto.

Seria inusitado encontrar uma celebridade fritando um ovo, pois, devido à condição financeira que as pessoas dessa classe atingem, não seria necessário realizarem tarefas domésticas e/ou tão prosaicas. Geralmente elas têm empregados para realizar serviços como esse. Ademais, o ovo é um alimento de custo muito baixo e, por isso, é uma comida típica de classes menos favorecidas economicamente. Mas ao falar de si mesma de modo tão simples e rotineiro, a cantora projeta a imagem de uma mulher "sem frescuras", isto é, uma mulher como outra qualquer. Aqui, ela se alinha à mulher comum, às pessoas comuns, realçando uma identidade positiva e coletiva. 
$\begin{array}{llllllll}\text { R } & \text { E } & \text { V } & \text { I } & \text { S } & \text { T } & \text { A } & \text { N. } 24-2012.2-\text { VICTORIA WILSON E AMANDA ALMEIDA }\end{array}$

Ao ser indagada sobre seu relacionamento com os fãs, no penúltimo bloco de perguntas da entrevista, observamos outra projeção da artista em face do contexto da interação: ela cria uma imagem de uma pessoa amigável e simpática. Quando afirma que alguns se tornaram amigos e cita exemplos, cria a imagem de alguém acessível: "Alguns se tornaram amigos, como a Luciana Moraes (webmaster) e a dramaturga Daniela Pereira de Carvalho, que escreve os textos do show".

Com isso, além de projetar atributos socialmente aprovados a seu próprio self, a cantora coopera para a comunicação, ao adotar estratégias de polidez positiva. Dentre as mais evidentes, podem-se destacar duas máximas de Brown e Levinson (1987): "Exagere o interesse, a aprovação e a simpatia pelo outro" e "Simule ou explicite reciprocidade".

Torna-se evidente, desse modo, que a cantora Paula Toller visa a manter a cooperação e a mútua preservação das faces na interação com a jornalista e seus fãs. Para isso, faz uso principalmente de estratégias de polidez positiva definidas por Brown e Levinson (1987). Além disso, busca construir a imagem pública de uma mulher simples, que se dedica bastante ao que faz para obter os melhores resultados e que se relaciona muito bem com sua equipe profissional e seus fãs.

\subsubsection{A construção realizada pela entrevistadora em sua publicação - o dano à face e a ação reparadora da Ombudsman}

Para elaborar o texto da entrevista divulgado no jornal, a jornalista baseou-se nas informações adquiridas na entrevista por e-mail, fato determinante para a construção de um esquema de conhecimento sobre o universo da cantora, cujo reflexo nesse texto acabou por gerar um conflito. Mas a existência desse esquema de conhecimento mostra-se anterior à entrevista e isso se torna notório quando, em suas perguntas, a jornalista cita palavras de outrem sobre sua interlocutora - "sua assessora diz que [...]" e "as pessoas que convivem com você dizem que [...]".

Cumpre notar que cada evento comunicativo é marcado por expectativas, um dos elementos de sua construção e negociação. Tannen e Wallat (1986) caracterizam o background dos participantes apresentando, entre as estruturas de expectativa, os esquemas. Esses configuram unidades de conhecimento, pois dizem respeito ao que o indivíduo pode recuperar em sua memória quanto aos lugares, objetos e pessoas, por exemplo, que conhece, direta ou indiretamente. 
$\begin{array}{llllllll}\text { R } & \text { E } & \text { V } & \text { I } & \text { S } & \text { T } & \text { A } & \text { N. 24-2012.2-VICTORIA WILSON E AMANDA ALMEIDA }\end{array}$

Entretanto, os esquemas não são fixos. As estruturas de expectativa, na verdade, estão em constante (trans) formação. Em nosso corpus, nota-se que, mesmo antes da entrevista, já havia um esquema de conhecimento acerca da artista. Porém, em seu encontro (virtual) com a entrevistadora, ela poderia ter correspondido ou não às expectativas em relação à sua imagem, utilizando procedimentos de elaboração de face por meio dos quais a imagem se (re) constrói.

Quanto a esse movimento, cabe esclarecer que tomamos o self ou a identidade aqui como uma construção permanente que os indivíduos realizam do mundo e de si mesmos. Hall (2001, p. 222) assinala que ao invés de pensarmos em identidade como um fato já concluído, “devemos pensar como uma produção que nunca está completa, que está sempre em processo, sempre constituída dentro e não fora da representação". É interessar pontuar, então, que o uso da linguagem está associado diretamente à construção de identidade. Os discursos são parte da vida e moldam os gêneros e é "através dos enunciados concretos que a vida entra na língua" (BAKHTIN, 2003, p. 265).

$\mathrm{Na}$ entrevista que analisamos, Paula Toller apresenta sua percepção sobre si mesma, mas seu discurso não pode ser uma definição absoluta de quem ela é, uma vez que a identidade não poderia estar concluída e já que o discurso de outros sobre ela também será fundamental para a construção de sua identidade. A entrevistadora alia, então, suas palavras a depoimentos de outras pessoas que trabalham com/para a artista. Lança mão ainda de observações do comportamento de Paula Toller durante um show do Kid Abelha, banda da qual é vocalista.

A partir desses dados, é elaborado um texto em que Mônica Bergamo cita as palavras de Paula Toller na entrevista, mas ao leitor são veladas as perguntas feitas e são apresentadas apenas algumas respostas. É possível afirmar que a reprodução foi fiel em praticamente todo o texto. Mas o problema surge quando, em novo contexto, as palavras assumem outras motivações pragmáticas, conforme podemos ver no anexo.

No texto de divulgação da entrevista, encontra-se o título "Abelha Rainha”, um jogo entre o nome da banda "Kid Abelha" e uma metáfora que atribui a Paula Toller papel central no grupo, como podemos ler abaixo:

Paula Toller comanda a volta do Kid Abelha e diz que fama de temperamental é elogio 4

(Grifo meu)

\footnotetext{
${ }^{4}$ Disponível em: http://www1.folha.uol.com.br/fsp/ilustrad/fq0105201108.htm. Acesso em 10 de setembro de 2012.
} 
$\begin{array}{llllllll}\text { R } & \text { E } & \text { V } & \text { I } & \text { S } & \text { T } & \text { A } & \text { N. 24-2012.2-VICTORIA WILSON E AMANDA ALMEIDA }\end{array}$

Esse jogo de palavras já provoca um ruído, sugere uma divergência entre o depoimento da cantora e a impressão geral da jornalista, pois, ao falar de seus companheiros de trabalho, a cantora fala de comer pizza com os mesmos, por exemplo, buscando situá-los no enquadre amizade, grupo/equipe e não no enquadre exclusivamente ligado ao trabalho no qual a cantora assumiria o papel central. Observemos as expressões utilizadas pela cantora nesse trecho da entrevista (não divulgado):

Tenho o prazer de trabalhar com gente talentosa e que se compromete. E faço muitos amigos entre os colegas. Pessoas por quem tenho o maior carinho e com quem saio para comer pizza. Eu adoro minha roda, poder jantar 1 h da manhã depois do show! (Grifos meus).

Outro ponto divergente é o relacionamento de Paula Toller com seus fãs. Enquanto a celebridade tenta se mostrar acessível e amigável na entrevista, os fatos noticiados pela jornalista mostram o oposto. Um fã, após o show, beija a cantora e lhe diz: "Sou seu fã desde sempre”. Ela não responde. Todos aguardam para tirar uma foto com ela, mas ela apenas se dispõe a tirar uma foto coletiva. De acordo, com o jornal ainda, ela "evita proximidade maior com os fãs" e, segundo um de seus seguranças, "ela não gosta de flashes, nem que toquem nela".

Em outro trecho, encontramos a seguinte afirmação: "Um produtor aborda a cantora: o governador do Paraná, Beto Richa, está na plateia. Quer visitá-la depois do show. 'Qual é o nome dele?', pergunta ela." O fato revela certo desdém da vocalista por uma pessoa cujo prestígio social é significativo, um representante político da cidade onde a cantora se apresenta com seu grupo. Há uma total falta de tato e consideração da cantora por aqueles que lhe atribuem importância e consideração. Nesse ponto, cria-se uma ruptura entre a imagem criada pela cantora no texto do e-mail e nas palavras reproduzidas pela jornalista.

No texto divulgado na Folha de São Paulo, a jornalista faz uso de seu próprio esquema de conhecimento acerca da cantora e orienta a entrevista para uma direção oposta, (des) construindo a imagem pública (positiva) da artista.

A colunista comete outro deslize ao apresentar como subtítulo do texto a seguinte inscrição: "Paula Toller comanda a volta do Kid Abelha e diz que fama de temperamental é elogio" (Grifo meu). Na verdade, o que a cantora considerou elogio foi a fama de "exigente e profissional", conforme destacamos da entrevista por e-mail: 
$\begin{array}{llllllll}\text { R } & \text { E } & \text { V } & \text { I } & \text { S } & \text { T } & \text { A } & \text { N. } 24-2012.2 \text {-VICTORIA WILSON E AMANDA ALMEIDA }\end{array}$

Coluna MB - As pessoas que convivem com você dizem que é uma pessoa 'exigente e profissional'. Você concorda? Acha que tem atitude diferente do padrão brasileiro?

PT - É um elogio, mas não comparo com os outros. Eu me exijo muito, eu sofro com as coisas, não durmo se tem algo errado. Tenho o prazer de trabalhar com gente talentosa e que se compromete. E faço muitos amigos entre os colegas. Pessoas por quem tenho o maior carinho e com quem saio para comer pizza. Eu adoro minha roda, poder jantar 1h da manhã depois do show!

Observamos que ao enviar as perguntas, a colunista do jornal Folha de São Paulo respeitou a máxima de modo de Grice, sendo bastante clara com sua entrevistada, sem, no entanto, ferir sua face. Fez sua contribuição provendo para a entrevistada nem mais e nem menos do que seria fundamental para uma boa compreensão de suas perguntas. Respeitou, portanto, a máxima da quantidade também. Mas na divulgação da entrevista, é clara a ameaça à face da cantora quando comparamos as duas situações. Portanto, a jornalista fere a máxima da qualidade de Grice. Afinal, o que a jornalista afirma não é verdade.

Nesse contexto, Paula Toller encontra argumento para invalidar o texto, qualificando-o em seu blog como "lamentável", numa busca de salvar sua própria face. A ruptura do equilíbrio na interação torna-se, assim, evidente.

É necessária então uma reparação do dano à face da cantora para que o jornal salve sua imagem institucional também. Observe-se a ação reparadora da face executada pela Ombudsman do jornal Folha de São Paulo, numa publicação endereçada à vocalista do Kid Abelha:

Cara Paula,

você tem razão sobre a frase que aparece abaixo do título "Abelha rainha". O jornal diz que você considera "um elogio" ser chamada de temperamental, mas não foi isso que você disse.

Embora a Ombudsman reconheça que houve um erro, não se trata apenas de uma troca lexical como ela busca retratar, mas trata-se da construção de uma imagem pública que diverge da que Paula Toller tenta elaborar ao longo da entrevista. Esse é ponto principal do conflito.

Por tudo isso, fica claro que a interação não alcançou sucesso. $\mathrm{O}$ fracasso do ato comunicativo se revela no comentário da cantora em seu blog, considerando a publicação "lamentável": 
$\begin{array}{llllllll}\text { R } & \text { E } & \text { V } & \text { I } & \text { S } & \text { T } & \text { A } & \text { N. 24-2012.2-VICTORIA WILSON E AMANDA ALMEIDA }\end{array}$

Paula Toller tem apenas um segurança pessoal, que não dá entrevistas. As lamentáveis declarações publicadas abaixo não partiram da equipe Kid Abelha nem representam o pensamento dos artistas ou de seus representantes.

Pela resposta da Ombudsman, o erro foi admitido, sem contudo ser devidamente esclarecido. Tanto a nota do blog quanto a resposta da Ombudsman são posteriores à entrevista e revelam o insucesso da interação: a falta de tato também da jornalista em adaptar as palavras da cantora, de acordo com sua conveniência ou propósito. Mas, afinal, o que de fato a jornalista pretendia? Por que solicitar uma entrevista a uma cantora, fazer com que ela "perdesse seu tempo" (apesar da publicidade e das prováveis repercussões positivas decorrentes dessa interação) para depois desconstruir com outros fatos a face positiva da cantora junto ao público leitor e a seus fãs? Poderíamos dizer que a entrevista foi bem sucedida nesse caso?

Consideramos, portanto, o fato de que a jornalista foi impolida; demonstrou ineficiência e impropriedade na organização de seus esquemas de conhecimento e na interação com sua entrevistada. $\mathrm{O}$ trabalho realizado pela jornalista não faz jus à qualidade dos profissionais do jornal Folha de São Paulo, ou da imagem que nós, leitores, temos dos profissionais que lá trabalham. Assim, podemos dizer que houve, de fato, um problema de comunicação que atingiu a cantora, a jornalista e todos os fãs que tiveram acesso à entrevista (ou matéria?) publicada no jornal.

\section{Considerações finais}

É possível perceber que o arranjo social organizado e compartilhado de uma entrevista tradicional se altera quando esse ato comunicativo migra para o espaço virtual. A Internet propõe uma interação apoiada em ausência real/ física dos interactantes e, no caso do $e$-mail, marcada também pela assincronia. Mas se por um lado o jornalista alcança a entrevista com mais rapidez, por outro, pode não ter as mesmas chances de obtê-la.

É notório que no espaço virtual, a concretização do propósito de quem realiza a entrevista se torna uma possibilidade mais instável, o que exigirá maior habilidade do profissional da comunicação. Numa entrevista a ser veiculada na televisão, ainda que o programa não seja "ao vivo", uma vez que se faça a primeira pergunta, palavras e imagens já estarão sendo gravadas. Mas, por trás da tela de um computador, recebendo o bloco de 
$\begin{array}{llllllll}\text { R } & \text { E } & \text { V } & \text { I } & \text { S } & \text { T } & \text { A } & \text { N. 24-2012.2-VICTORIA WILSON E AMANDA ALMEIDA }\end{array}$

perguntas enviado por um entrevistador, o artista pode se negar a dar prosseguimento à interação com mais facilidade.

Em todos os casos, sempre que há uma interação é possível ocorrer um (ou mais de um) ato de ameaça à face dos envolvidos. No caso das perguntas por e-mail, todo cuidado é pouco, dada a assincronia entre o recebimento das perguntas e o envio de suas respostas. Por isso, o jornalista deve zelar ainda mais pela preservação da face do seu interlocutor nessa situação interativa. Na entrevista por e-mail, realizada pela jornalista Mônica Bergamo com a cantora Paula Toller, observamos, curiosa e paradoxalmente (talvez) o emprego de mais estratégias de reparação de face por parte da cantora do que da parte da jornalista. Observamos também como foram frouxas as tentativas mais amigáveis da jornalista para evitar efeitos perlocutórios indesejáveis, sobretudo, na coluna publicada no jornal baseada na entrevista.

A polidez consiste justamente no esforço de manter e reparar a própria face e a do outro, e a face negativa corresponde ao território de cada indivíduo. Parece que a jornalista desconhece ou não faz uso (d) esses princípios. Cabe pontuar que nas respostas a cantora se valeu de máximas da polidez estabelecidas por Brown e Levinson quando elogiou seus fãs e sua equipe profissional e, ainda, procurou contornar certas "alfinetadas" da jornalista. Isso foi possível, a nosso entender, graças ao fato de ter sido uma entrevista por e-mail. O suporte, nesse caso, pode atuar como um meio facilitador para promover interações mais harmoniosas.

Infelizmente, não podemos afirmar que a publicação da entrevista tenha atingido as condições de felicidade ou sucesso da interação. Se, de acordo com Goffman, as interações estão apoiadas sobre um princípio auto-regulador, como um ritual de comportamento, as ameaças à face, segundo esse princípio, seriam evitadas ou contornadas "de tal forma que os participantes, em conjunto, possam atingir seu objetivo comum, apesar de diferentemente motivados" (GOFFMAN, 1980, p. 94). O que houve entre a entrevista concedida e a publicação adaptada? Que imagem a jornalista pensava criar a respeito da cantora? E, na verdade, que imagem a jornalista queria preservar: a sua ou a da artista? Parece-nos que a jornalista, ao não preservar a face da sua entrevistada, acabou também por não preservar a sua própria e o resultado de todo esse trabalho foi negativo, além de empobrecedor.

\section{Referências bibliográficas:}

AUSTIN, J. L. Quando dizer é fazer: palavras e ação. Porto Alegre: Artes Médicas, 1990.

BAKHTIN, M. Os gêneros do discurso. In: Estética da criação verbal. 4. ed. São Paulo: Martins Fontes, [1979] 2003, p. 261-306. 
$\begin{array}{llllllll}R & \text { E } & \text { V } & \text { I } & \text { S } & \text { T } & \text { A } & \text { N. 24-2012.2-VICTORIA WILSON E AMANDA ALMEIDA }\end{array}$

BONINI, A. Entrevista por e-mail: pragmática de um gênero (des) conhecido ou problemas comunicativos na variação do gênero. In: Revista de Letras, n. 22, v. 1-2, Fortaleza, Edições UFC, jan./dez. 2000.

BROWN, P.; LEVINSON, S. Politeness: some universals in language usage. Cambridge: Cambridge University Press, 1987.

CULPEPER, J. Towards an anatomy of impoliteness. Journal of Pragmatics 25, 1996: 34967.

GOFFMAN, E. A elaboração da face. Uma análise dos elementos rituais da interação social. In: FIGUEIRA, S. (Org.). Psicanálise e ciências sociais. Rio de Janeiro: Francisco Alves, 1980, p. 76-114.

A situação negligenciada. In: RIBEIRO, B. T.; GARCEZ P. M. (Orgs.). Sociolinguística Interacional. Porto Alegre: Age, 2002 [1964], p. 11-15.

GRICE, H. P. Logic and conversation. In: COLE, P., MORGAN, J. (Eds.). Speech acts. New York: Academic Press, 1975.

GUMPERZ, J. Convenções de contextualização. In: RIBEIRO, B. T.; GARCEZ, P. M. (Orgs.). Sociolinguística Interacional. São Paulo: Loyola, 2002 [1982].

HOLANDA, Sérgio Buarque de. Raízes do Brasil. São Paulo: Companhia das Letras, 1995 [1998]. 6. reimpressão. [1939].

MARCONDES, Danilo. A pragmática na filosofia contemporânea. Rio de Janeiro: Jorge Zahar Ed., 2005.

OLIVEIRA, Maria do Carmo Leite. Polidez e interação. In: CALDAS-COULTHARD, C. R.; SCLIAR-CABRAL, L. Desvendando discursos. Conceitos básicos. Florianópolis: Ed. UFSC, 2008, p. 197-224.

SEARLE, John. Os actos de fala. Coimbra: Almedina, 1984.

TANNEN \& WALLAT, C. Interactive frames and knowledge schemas in interaction. In: TANNEN, D. (Ed.) Framing in discourse. NEW YORK: Oxford University Press, 1986.

WILSON, V. Motivações pragmáticas. In: MARTELOTTA, M. (Org.). Manual de Linguística. São Paulo: Contexto, 2008, p. 87-110.

\section{Conditions for happiness and the work of the faces in interviews by $e$-mail}

Abstract: Considering the role of politeness in social interaction, this article aims to reflect on the importance of politeness in interactional situations such as an interview by e-mail that 
requires specific rearrangements and reconstructions of social roles and self and preservation of face strategies in the conveyance of information received and the way that it is later published and disseminated in newspapers. In an interview by e-mail, if the journalist reaches his/her communicative purpose more easily with the publication, on the other hand, the respondent produces his/her responses more carefully and cautiously, as he/she has more time to work for the protection of his/her face. Thus the ritualized newspaper interview somehow suffers a variation. In this complex sharing structure that is established between he interactants, it is necessary to identify the genre's condition for happiness. The analysis is carried out in light of Interactional Sociolinguistics so as to contribute to the discussion and resolution of social and pragmatic problems related to this genre, that, although new, is increasingly common in contemporary society.

Key words: Politeness. Interaction. Face. Interview by e-mail. Journalism.

Recebido em: 12 de dezembro de 2012.

Aprovado em: 15 de janeiro de 2013. 


\section{Anexo 1}

\section{Entrevista na íntegra}

Coluna Mônica Bergamo - Quando e como você diagnosticou diabetes? O que mudou na sua vida desde então?

Paula Toller - Fui diagnosticada com Diabetes tipo 1 em 2009, por acaso, numa consulta com o dermatologista q me trata há 20 anos. Eu estava magra demais e ele desconfiou. Foi um baque, mas agora já estou me adaptando, embora tenha q seguir uma rotina de alimentação e exercícios bem rígida, e usar insulina.

Coluna MB - Há quantos anos você faz análise? O que você enxerga como resultado dessa experiência (inclusive canções)?

PT - Análise evita enferrujar o cérebro. É bom para dar valor às coisas q realmente têm valor, e deixar rolar o q pode ser deixado rolar. Aos poucos vc vai conhecendo melhor essa maquininha q diferencia os seres humanos dos outros seres. E dá um suporte para as inevitáveis barras pesadas. Eu tinha muito problema com inspiração pra escrever, era cheia de "não-me-toques", agora, se tenho q escrever, vou lá e escrevo. É bem óbvio.

Coluna MB - Sua assessora diz que, embora você não esteja em todas as festas e circuitos badalados do Rio, você costuma andar pelas ruas na boa, como para ir ao salão etc. Como é sua rotina quando longe dos palcos?

PT - Eu vou a festas de amigos, vou a lançamentos e shows de amigos, mas não trabalho com "presença de celebridade". Meu trabalho é com música. O Rio de Janeiro permite isso, por que é uma "celeb-cidade". Tenho rotinas q vão se alternando e modificando, dia de show é mais caótico, por causa das viagens. Dois dias antes de qualquer show eu já estou me preparando, não tomo nem um drink, por exemplo. Antes de uma estréia como essa agora, então, eu já entro um mês antes no processo. Mas sair eu saio rápido, sou capaz de chegar de um show para 30 mil pessoas e fritar um ovo ainda maquiada e de salto.

Coluna MB - As pessoas que convivem com você dizem que é uma pessoa "exigente e profissional". Você concorda? Acha que tem atitude diferente do padrão brasileiro?

PT - É um elogio, mas não comparo com os outros. Eu me exijo muito, eu sofro com as coisas, não durmo se tem algo errado. Tenho o prazer de trabalhar com gente talentosa e que se compromete. E faço muitos amigos entre os colegas. Pessoas por quem tenho o maior carinho e com quem saio para comer pizza. Eu adoro minha roda, poder jantar $1 \mathrm{~h}$ da manhã depois do show!

Coluna MB - Como cuida da aparência? Faz esportes (tênis?), rituais estéticos, maquiagem, cabelo?

PT - Na infância, eu sempre fui mais pra atleta, energética, brincadeiras de menino, do que feminina e delicada. Agora gosto de me cuidar, gosto q me admirem no palco, na TV. O Lui, tb me dá o maior apoio, não me deixa desanimar. Fiquei muito mais bonita depois q me casei com ele. 
Coluna MB - Você gosta de ser elogiada por fãs? Como lida com o assédio dos fãs? PT - Meus fãs são maravilhosos, me mimam bastante. Alguns se tornaram amigos, como a Luciana Moraes (webmaster) e a dramaturga Daniela Pereira de Carvalho, que escreve os textos do show.

Coluna MB - Por que preferiu dar entrevista por e-mail a falar no telefone ou pessoalmente?

PT - Para poupar a voz.

Obrigada

Paula Toller 


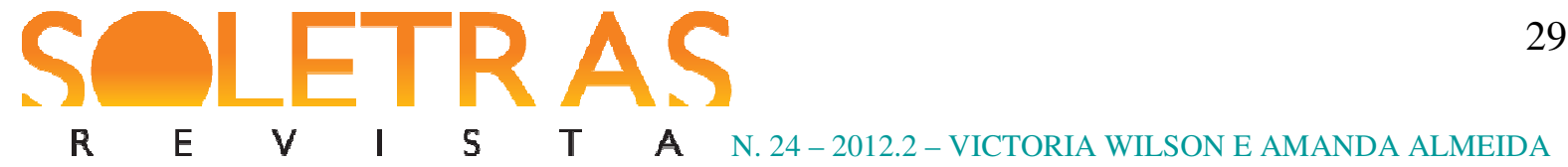

\title{
Anexo 2
}

\section{Texto de divulgação da entrevista}

\author{
Folha de São Paulo
}

Coluna Mônica Bergamo

\section{ABELHA RAINHA \\ Paula Toller comanda a volta do Kid Abelha e diz que fama de temperamental é elogio}

Paula Toller, 48, chega cedo para a passagem de som do primeiro show de "Glitter de Principiante", a turnê de reencontro do Kid Abelha, no Teatro Guaíra, em Curitiba. Três anos depois de se dedicarem a carreiras solo, os integrantes do grupo (além dela, o saxofonista George Israel e o guitarrista Bruno Fortunato) se juntaram para um roteiro de apresentações e a gravação de um DVD que celebrará, no ano que vem, os 30 anos de criação da banda.

No próximo sábado, 7, eles tocam no Credicard Hall, em São Paulo. No dia 14, no Citibank Hall do Rio.

No Paraná, a ansiedade era grande. "Estou há três dias sem dormir", dizia Mauro Benzaquem, empresário da banda. "A Paula também. É a capitã da nave. Não quer conversa até ver que tem o show', afirmava à repórter Thais Bilenky.

O cenário encomendado não ficou pronto a tempo e a equipe teve que improvisar: instalou um painel de LED onde eram exibidas figuras de elefantes, letras de músicas e... Israel e Fortunato se mantinham relaxados. Já Paula gesticulava, inspecionava a mesa de som, conversava com os músicos, dava ordens à equipe.

A produtora Catia Dartora diz às assessoras de imprensa que Paula só queria fotos "descontraídas fake", aparentando espontaneidade, mas ensaiadas. Ficam todas tensas. Nem isso acontece: a cantora se tranca no camarim quase duas horas antes do show.

O guitarrista afirma que ele e o saxofonista cuidam "mais da parte instrumental". "A Paula quis ficar à frente do conceito. Estamos deixando ela à vontade."

Nos três anos em que tocou sua carreira solo, Paula descobriu que estava com diabetes. Em 2009, foi ao dermatologista e, por acaso, diagnosticou a doença. "Estava magra demais e o médico desconfiou. Foi um baque, mas agora já estou me adaptando, embora tenha que seguir uma rotina de alimentação e exercícios rígida, usar insulina”, conta.

Pouco antes do show, ela deixa o camarim. Recebe elogios pelo visual, aos quais não responde. Um produtor aborda a cantora: o governador do Paraná, Beto Richa, está na plateia. Quer visitá-la depois do show. "Qual é o nome dele?", pergunta ela.

Com uivos de "Gostosa!", o público recepciona Paula e o Kid Abelha. Ela segue em sua performance. "Gosto que me admirem no palco, na TV. O Lui [Farias, seu marido], me dá o maior apoio. Fiquei muito mais bonita depois que me casei com ele", diz. Evita proximidade maior com os fãs. "Ela não gosta de flashes, nem que toquem nela. Dou logo um tabefe quando começam a abraçar", diz um de seus seguranças.

Numa apresentação em João Pessoa, nos anos 90, uma cozinheira invadiu o palco. Ao tentar se afastar, a cantora levou um arranhão no braço. Sangrando, interrompeu o show e foi ao Instituto Médico Legal fazer exame de corpo de delito. "Ficou buzinando por séculos. 'Como você deixou essa maluca entrar?!', diz o segurança.

No palco, Paula conta que a canção "Dizer não é dizer sim" nasceu depois de seu psicanalista observar que suas letras começavam com negativas: "Não estou disposto...", 


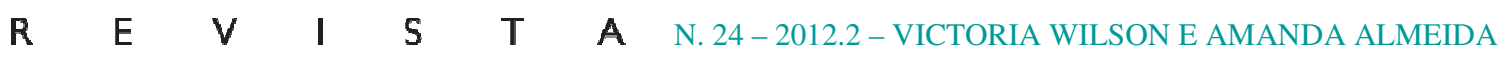

"Nada sei...". À coluna, ela diz que "tinha muito problema com inspiração, era cheia de não me toques. Agora, se tenho que escrever, vou lá e escrevo".

O espetáculo acaba. Richa está a postos no camarim. Dá beijos nas bochechas da cantora. "Sou seu fã desde sempre". Ela não responde. Ele pede para tirar uma foto, mas a bateria da máquina acaba na hora errada. Fãs fazem fila na porta do teatro.

Quarenta minutos depois, a cantora dá o ar da graça. Senta-se no chão com os fãs por cinco minutos e posa para uma foto coletiva. Ilizandro Schmit, 28, trouxe CDs da banda, mas ela não os autografa. Passada a bagunça, ele percebe que sua câmera sumiu. "Não merecemos esse tratamento. É melhor vocês dizerem: 'A Paula não vai atender. Vão embora, por favor'. Aquela foto [coletiva] ninguém vai querer"”.

A cantora tem fama de temperamental. "É um elogio", rebate Paula Toller. "Eu me exijo muito, sofro com as coisas, não durmo se tem algo errado. Tenho o prazer de trabalhar com gente talentosa e que se compromete". Segundo seu empresário, o combinado dela é: "Eu não erro, você não erra. Ok?". Reservada, só sai com os amigos: "Não faço presença de celebridade. Meu trabalho é com música".

\section{Nota do Blog}

Paula Toller tem apenas um segurança pessoal, que não dá entrevistas. As lamentáveis declarações publicadas abaixo não partiram da equipe Kid Abelha nem representam o pensamento dos artistas ou de seus representantes.

\section{Resposta da Ombudsman, jornal Folha de São Paulo}

Cara Paula,

você tem razão sobre a frase que aparece abaixo do título "Abelha rainha". O jornal diz que você considera "um elogio" ser chamada de temperamental, mas não foi isso que você disse.

Atenciosamente,

Suzana Singer

Ombudsman - Folha de São Paulo, 04/05/2011. 